\title{
Valuation of travel time reliability from a GPS-based experimental design
}

\author{
Carlos Carrion*, David Levinson \\ University of Minnesota, Department of Civil Engineering, 500 Pillsbury Drive SE, Minneapolis, MN 55455, USA
}

\section{A R T I C L E I N F O}

\section{Article history:}

Received 9 September 2010

Received in revised form 23 October 2012

Accepted 29 October 2012

\section{Keywords:}

Time reliability

GPS

Route choice

Random utility

I-394 HOT

MnPass

Mixed logit

Bootstrap

\begin{abstract}
A B S T R A C T
In the Minneapolis-St. Paul region (Twin Cities), the Minnesota Department of Transportation (MnDOT) converted the Interstate 394 High Occupancy Vehicle (HOV) lanes to High Occupancy Toll (HOT) lanes (or MnPASS Express Lanes). These lanes allow single occupancy vehicles (SOVs) to access the HOV lanes by paying a fee. This fee is adjusted according to a dynamic pricing system that varies with the current demand. This paper estimates the value placed by the travelers on the HOT lanes because of improvements in travel time reliability. This value depends on how the travelers regard a route with predictable travel times (or small travel time variability) in comparison to another with unpredictable travel times (or high travel time variability). For this purpose, commuters are recruited and equipped with Global Positioning System (GPS) devices and instructed to commute for two weeks on each of three plausible alternatives between their home in the western suburbs of Minneapolis eastbound to work in downtown or the University of Minnesota: I-394 HOT lanes, I-394 General Purpose lanes (untolled), and signalized arterials close to the I-394 corridor. They are then given the opportunity to travel on their preferred route after experiencing each alternative. This revealed preference data is then analyzed using discrete choice models of route. Three measures of reliability are explored and incorporated in the estimation of the models: standard deviation (a classical measure in the research literature); shortened right range (typically found in departure time choice models); and interquartile range (75th-25th percentile). Each of these measures represents distinct ways about how travelers deal with different sections of reliability. In all the models, it was found that reliability was valued highly (and statistically significantly), but differently according to how it was defined. The estimated value of reliability in each of the models indicates that commuters are willing to pay a fee for a reliable route depending on how they value their reliability savings.
\end{abstract}

(c) 2012 Elsevier Ltd. All rights reserved.

\section{Introduction}

The issue of travel time reliability is becoming more critical to users of transportation networks. Historically, research on route choice behavior focused on expected travel time without consideration of its variability. However, surface transportation networks have matured in developed nations. This situation has been characterized by an inability to increase network capacity with additional links or lanes, because of small benefit-cost ratios (none to small economic advantage), possible negative effects (new links might make the network worse - as in the Braess Paradox), physical constraints (e.g. no space for expansion), difficulties in acquiring new rights of ways, and others. In contrast, travel demand (the number of users in the network) has been able to catch up or in some cases surpass the supply (network infrastructure) leading to congestion.

\footnotetext{
* Corresponding author. Tel.: +1 612626 0024; fax: +1 6126267750.

E-mail addresses: carri149@umn.edu (C. Carrion), dlevinson@umn.edu (D. Levinson).

URL: http://nexus.umn.edu (D. Levinson).
} 
However, questions arise about which aspects of congestion are most costly, the higher travel times, the unpredictability of travel times (requiring earlier departures or causing potentially late arrivals), or the potential monetary cost of relieving congestion.

For this reason, considerable research into the connections between travel time variability and behavioral responses has been completed to date. This has generally included the development of theoretical models and empirical analysis of the relationships that affect both travel time reliability and traveler reactions. The focus has been directed mainly to four areas: departure time choice, traveler perception of reliability, mode choice, and route choice. In the case of route choice, the travel time of a particular path could be less important than how reliably the traveler can predict the duration of the trip. If travelers can ensure reaching their destinations in a time-certain manner, they may be willing to drive on paths with longer travel times rather than risking the use of paths that possess shorter travel times, but that entail greater risks of arriving late.

The main objective of this study is to estimate the value of travel time reliability of commuters using Interstate 394 in Minneapolis. This objective is the link to the implicit hypothesis that in addition to travel time both travel cost and travel time variability are significant factors in route choice preference, and it also leads to the hypothesis that travelers are willing to pay for enhancing their commute travel time reliability. In other words, the study will examine the extent to which the subjects value travel time reliability by comparing the variability of the time required to travel each of the three routes with the drivers' revealed preference (ascertained from global positioning system (GPS) tracking data) for the routes.

The remainder of this study addresses the following topics in order: literature review, data (covers sample descriptive statistics, experimental design, and GPS data processing), theory (including analytical framework and the econometrics model specification), results, and conclusions.

\section{Literature review}

This review presents a selective summary of relevant results (as the focus of this study is in the estimation of VOR from revealed preference data) to this research, and thus providing a comprehensive review is not the purpose of this study. Readers should refer to review treatments of value of reliability for a more complete treatment such as Noland and Polak (2002), Small and Verhoef (2007, Chapter 2, pp. 52-54), Li et al. (2010), Nakayama (2010), and Carrion and Levinson (2012).

\subsection{Route choice and travel time reliability}

Route choice behavior is not entirely encapsulated by time and distance. Other factors (such as aesthetic scenery, network knowledge, and trip information) are also linked to the explanation of this phenomenon (Pal, 2004). In the case of reliability, the traveler is influenced by the quality of service provided by the links in a road network. This service is vulnerable to deterioration by recurrent (e.g., bottleneck congestion) or non-recurrent (e.g. crashes, weather, construction, or natural disasters) adverse forces. The detrimental effect of these forces can be quantified in performance measures such as connectivity and travel time reliability.

The genesis of these reliability measures has depended on road network problems in distinct periods of time. Connectivity was a major issue in the 1960s. The study of link disruptions was essential, because of the sparse nature of the network; the loss of a link resulted in long detours. On the other hand, travel time reliability has received increased attention lately. It is usually regarded as an indicator of the delays experienced by travelers because of the uncertainty present in the road network (Nicholson et al., 2003). This uncertainty is divided in three components by Wong and Sussman (1973): variation between seasons and days of the week; variation by changes in travel conditions because of weather and crashes or incidents; and variations attributed to each traveler's perception. Nicholson and Du (1997) lists also the components of uncertainty as variations in the link flows and variations in the capacity.

\subsection{Empirical research}

The initial research related travel time reliability is of qualitative nature, and mainly based on questionnaires identifying travelers' preferences. For example, Vaziri and Lam (1983) asked commuters to list and rank possible reasons affecting their route choice. The results (directly) related to reliability were: "it has fewer accidents or unexpected tie-ups" (ranked fourth); and "it has smaller variation in trip times" (ranked eight). Similar results were found by Chang and Stopher (1981) with travel mode preferences. Furthermore, Prashker (1979) was the first to explicitly account for reliability; he included different levels of variation for variables such as in-vehicle travel time, parking search time, and bus waiting time.

Quantitative studies proceeded to emerge presenting methodologies to measure travel time reliability (e.g. mean-variance approach and scheduling approach), and using mostly stated preference data; it is difficult to find real examples (e.g. HOT lanes) that could be used for ascertaining reliability estimates with revealed preference (RP) data (Bates et al., 2001). Jackson and Jucker (1982) introduced the mean-variance approach through a survey administered to Stanford University employees; it consisted of paired comparison questions of hypothetical route alternatives. A pair was typically formed of two "usual" times and corresponding delays to each member of the pair. The highest delay was always given to the shortest "usual" time of the pair. The analysis of the subject's stated preference was done by optimizing an objective function (a linear programming problem) in which the expectation and variance of the travel times are variables. This method also allowed for the estimation of a degree of risk aversion parameter for the subjects. Jackson and Jucker found that some 
commuters prefer the more reliable route, even if the expected travel time is higher in comparison to other routes with shorter expected travel time, and higher uncertainty. This result agrees with the notion of a distribution of the degrees of risk aversion in the subjects. In addition, they noted that the mean-variance approach is useful and tractable. Abdel-Aty et al. (1997) used two stated preference techniques (a computer aided telephone interview and a mail-back survey) in order to investigate the effect of travel time reliability and traffic information on commuters. The first survey consisted of offering five options, each with two routes with distinct travel times (one with the same travel time for every day, and the other with different travel times on some days) for the travelers to choose, and the second one consisted of two routes (one presumably familiar to the subjects) with similar travel time variation scheme to the previous survey, but also included a section with traffic information. The analysis of the survey data was done with binary logit models including variables such as standard deviation, mean and gender. They found that commuters consider reliability characteristics in their route choice preference, and pay attention to travel information enough to be influenced in some scenarios to deviate from their usual routes. Another finding was that males tend to choose the uncertain route more than females.

Other research has focused on analyzing travel time reliability considering solely departure time choice. A factor that may influence route choice, as some travelers can change their departure times to combat the temporal effects of disadvantageous routes. This is likely especially for commuters, because they are usually bounded by time restrictions. Central research in this topic includes Gaver (1968), Small (1982), and Noland and Small (1995). The first introduced a theoretical framework for describing variability in travel decisions. He considered distinct head start strategies according to delay distributions. The second estimated an empirical scheduling model. The formulation proposed considers costs associated with early and late arrival, the travel time cost, and a fixed cost for lateness. He finds that travelers are more averse to arriving late than arriving early, and that arriving early registers as a disutility. The third extends Gaver (1968) by including travel time variability in the scheduling model, and analyzes the cases of uniform and exponential travel time distributions. A thorough review of these studies and others is available at Noland and Polak (2002). Other more recent studies (e.g. Tilahun and Levinson, 2010) have focused on investigating measures of travel time distributions different from traditional ones such as mean-variance. Tilahun and Levinson (2010) presents a travel time reliability measure consisting of two moments: the first representing on average how early the traveler has arrived by using that route; and the second representing on average how late that individual arrived by using that particular route. They assume that the deviation of the two moments (average late or average early) from the most frequent experience is a representative way of getting together the possible range and frequencies experienced by the travelers.

Recent revealed preference (RP) data appeared due to the introduction of High Occupancy Toll lanes (HOT). These HOT lanes provide an adequate experimental setting, because the HOT lane is enforced to maintain levels of free flow traffic, and thus the variation should be significantly smaller compared to the general purpose lanes. Small et al. (2005) and Small et al. (2006) utilized data collected on California State Route 91 (CA-91) in the morning (AM). The collection consisted of three surveys: the first survey was a telephone interview of actual travel (revealed preference), and the other two were mail-back questionnaires (the first one about actual travel [revealed preference], and the other one about hypothetical scenarios [stated preference]). The set of actual alternatives was composed of High-Occupancy Toll lanes (HOT) and General Purpose Lanes. Commuters using the HOT lanes require an electronic transponder to pay a toll, which varies hourly. It should also be noted carpools (High Occupancy Vehicles (HOVs)) are allowed in the HOT lanes with a discount. The set of hypothetical alternatives remained the same as the actual with the exception of changing the values of variables such as time, cost and reliability. These changes allowed for the preferences of the subjects to be inferred based on their unique pattern of responses to trade-offs among the different hypothetical scenarios. The data was analyzed by a discrete-choice model; a utility function was specified containing attributes for the alternatives including toll, travel time and reliability. This statistical model approach allows for the estimation of the well known value of time (VOT), and the value of reliability (VOR). The latter value represents the susceptibility of the commuters to (un) reliability in monetary terms, and it is calculated as the ratio between the parameters of travel reliability and travel cost (toll cost in the study). This VOR represents the marginal rate of substitution between travel cost, and travel reliability. Another important feature of the model is the inclusion of a carpool variable in order to control for systematic bias. However, besides all these similarities the studies differ in certain key areas.

The first study (Small et al., 2005) focuses solely in formulating a lane choice model (using mixed logit) by combining the RP and SP data. The results of the model indicate travel time and reliability to be significant, and that the heterogeneity in these factors is significant as well (thus implying the significance of the heterogeneity of VOT and VOR). In contrast, the second study (Small et al., 2006) models not only lane choice, but also vehicle occupancy and transponder acquisition. It also extends the previous study (Small et al., 2005) by using simulations to analyze distinct highway pricing policies besides the current one at CA-91. The policies simulated include: no toll, general purpose and HOV, general purpose and HOT, and combinations of the preceding cases. The objectives of these simulations is to point out the significance of the heterogeneous preferences of commuters to highway policymakers, and, as Small et al. points out, the current use of homogeneous preferences fails to account accurately for different policies working together. It should be noted that highway pricing policies are typically developed for congestion relief. The main notion being that congestion is a negative externality of the transportation system, and the use of pricing schemes will reduce any unnecessary trips, and persuade travelers to reconsider their activity patterns in time and space.

The limitations of the previous empirical studies are mostly related to their observational methodology. In the cases of Abdel-Aty et al. (1997) and Jackson and Jucker (1982), the observed route preferences of the subjects, as described earlier, are obtained by stated preference (SP) techniques; they consisted of hypothetical routes with distinct attributes (e.g. travel 
Table 1

Actual subjects vs. initial subjects.

\begin{tabular}{llllr}
\hline Sample & Initial subjects & Dropouts & Data loss & Remaining subjects \\
\hline August-08 & 28 & 10 & 6 & 12 \\
March-09 & 11 & 8 & 1 & 2 \\
September-09 & 15 & 7 & 4 & 4 \\
& $\mathbf{5 4}$ & & & $\mathbf{1 8}$ \\
\hline
\end{tabular}

Table 2

Summary of selected studies from the literature review.

\begin{tabular}{|c|c|c|c|}
\hline Study & Data (source and type) & Method & Results \\
\hline $\begin{array}{l}\text { Abdel-Aty } \\
\quad \text { et al. } \\
\quad(1997)\end{array}$ & $\begin{array}{l}\text { Phone Interviews and Mail-back Surveys of the Los } \\
\text { Angeles area morning commuters; Stated Preference } \\
\text { (SP) }\end{array}$ & $\begin{array}{l}\text { Choice models } \\
\text { (binomial logit) }\end{array}$ & $\begin{array}{l}\text { Commuters consider variability in their route choices; } \\
\text { Males tend to choose the uncertain route more than } \\
\text { females }\end{array}$ \\
\hline $\begin{array}{l}\text { Jackson } \\
\text { and } \\
\text { Jucker } \\
(1982)\end{array}$ & $\begin{array}{l}\text { Survey of Stanford University Employees; Stated } \\
\text { Preference (SP) }\end{array}$ & $\begin{array}{l}\text { LINMAP (Linear } \\
\text { Programming } \\
\text { technique) }\end{array}$ & $\begin{array}{l}\text { Some commuters prefer reliable routes even if the } \\
\text { expected travel time is higher }\end{array}$ \\
\hline $\begin{array}{l}\text { Small et al. } \\
\qquad(2005 \text {, } \\
\text { 2006) }\end{array}$ & $\begin{array}{l}\text { Phone Interviews and Mail-back Surveys of California } \\
\text { Route 1991s morning commuters; Stated Preference } \\
\text { (SP) and Revealed Prefrence (RP) }\end{array}$ & $\begin{array}{l}\text { Choice Models } \\
\text { (Mixed Logit), }\end{array}$ & $\begin{array}{l}\text { Heterogeneity is significant in VOT and VOR estimates, } \\
\text { and it must be taken in account for successful traffic } \\
\text { congestion policies such as HOV and HOT }\end{array}$ \\
\hline \multirow[t]{2}{*}{$\begin{array}{l}\text { Tilahun } \\
\text { and }\end{array}$} & Levinson (2009) & $\begin{array}{l}\text { Phone Interviews } \\
\text { and Mail-back } \\
\text { Surveys of I-394 } \\
\text { commuters; Stated } \\
\text { Preference (SP) }\end{array}$ & Choice Models (Random Intercept Binomial Logit). \\
\hline & $\begin{array}{l}\text { Commuters who are late have highest willingness to } \\
\text { pay to avoid delays especially in the afternoon in } \\
\text { contrast to those that are early/on time }\end{array}$ & & \\
\hline \multirow[t]{2}{*}{$\begin{array}{c}\text { Tilahun } \\
\text { and }\end{array}$} & Levinson (2010) & $\begin{array}{l}\text { Computer- } \\
\text { Administered } \\
\text { Survey; Stated } \\
\text { Preference (SP) }\end{array}$ & Choice Models (Random Intercept Binomial Logit) \\
\hline & $\begin{array}{l}\text { Commuters value reducing one minute of average } \\
\text { lateness close to reducing travel time }\end{array}$ & & \\
\hline
\end{tabular}

time). For this reason, the validity of the observed preferences may be affected by the lack of realism, and the subject's understanding of the abstract situations. Thus, the subject's route preferences may not be similar to the ones during their actual trips (see Louviere et al. (2000) and Hensher (1994) for discussions about SP vs. RP). In contrast Small et al. (2005) and Small et al. (2006) collected both RP (actual preferences of subject's lane choice) and SP (hypothetical scenarios to examine subject's lane choice) observations, and consequently enriched their statistical model by pooling both types of data. However, the nature of the survey methods employed did not allow for some of the variables to be measured during each of the subject's trips. For example, travel time was obtained by field measurements (performed by others instead of the subjects) corresponding approximately to the travel periods of the subjects. Thus, these measurements may have affected the accuracy of the data in the model. Other data collection techniques such as equipping the subject's vehicles with Global Positioning System (GPS) devices would have avoided said difficulties, and possibly extend the lane choice model into a route choice model by considering arterials near the subjects. Furthermore, a GPS device can collect a wealth of detailed commute level data, including travel time and distance, origin and destination pair with link-by-link trajectory, commute start and end times, and trip itineraries. Therefore, it is no surprise that, with dropping equipment costs, these devices have been used as of late for travel behavior studies, especially for route choice behavior. A few examples of these studies are: Li et al. (2004) (an inspection of the travel time variability in commute trips, and its effects on departure time and route choice, including cases with trip-chaining), Li et al. (2005) (an analysis of attributes determining whether to choose one or more routes in the morning commute), and Zhang and Levinson (2008) (an estimation of the value of information for travelers, and a comparison of the impact of information with other variables such as travel time, distance, aesthetics, ...). Further detail about GPS application to transportation research, including GPS data processing using Geographical Information System (GIS) environment (matching of trip points to road network digital line graphs [DLG]) can be found in Li (2004).

A summary of selected studies of this literature review is presented in Table 2.

\section{Experimental design}

\subsection{Description}

This study uses two electronic devices for measuring data: a logging Global Positioning System device (QSTARZ BTQ1000p GPS Travel Recorder powered by DC output from in-vehicle cigarette lighter); and a MnPass transponder. The latter 
provides information about toll data (amount, time, and date). The former allows the measurement of detailed commute level data including: travel times for each commute trip; distance traveled for each commute trip; time of day, and drivers' trajectories. Furthermore, this study is set on the I-394 High Occupancy Toll lanes (also known as MnPass lanes) in the Minneapolis-St. Paul metropolitan area in the United States. These lanes are described along with the methodology of the study subsequently.

\subsubsection{MnPass lanes}

In 2005, the I-394 MnPass lanes opened as Minnesota's first high-occupancy toll (HOT) lanes. The Minnesota Department of Transportation (MnDOT) authorized the conversion of the I-394 high-occupancy vehicle (HOV) lanes to HOT lanes. These lanes are formed by two parts: diamond lanes and reversible lanes. The diamond lanes are separated from the general purpose lanes (GPLs) by solid white lines, and include several access points (or gaps between solid white lines) to the lanes. These lanes are located between the intersections of I-394-I-494 and I-394-Highway 100. The reversible lanes are separated by barriers from the general purpose lanes (GPLs), and have their access points at the intersection of I-394-Highway 100 and also close to downtown Minneapolis. It should be noted that drivers are alerted of access points by signs as well of the current tolls for using the lanes. See Fig. 1.

The MnPass lanes allows transit vehicles, and carpoolers to use the lanes for free, except for single occupancy vehicles (SOVs). The latter can access the lanes by acquiring a MnPass transponder and opening a MnPass account. The system works by charging USD $\$ 40$ for opening an account, and the users pay a monthly fee of USD $\$ 1.50$ for transponder leasing, and any other charges are tolls that are paid according to the electronic signs.

The tolls of the MnPass lanes are restricted between the interval of USD\$0.25 and USD\$8.00, when the tolls are operating. The price is set according to the traffic density as measured by roadway sensors in the lanes (both diamond and reversible), and it is updated every $3 \mathrm{~min}$. The hours of operation are different for the diamond and reversible lanes. The diamond lanes operate eastbound between 6 and 10 AM, and westbound between 2 and 7 PM. The reversible lanes operate eastbound between 6AM-1PM, and westbound 2PM-5AM. The rest of the time the electronic signs do not charge SOV drivers. Moreover, the collected revenue from the MnPass is used to pay for the operation cost of the system.

\subsubsection{Methodology}

After the subjects were recruited (see Section 4.1 for details), an experimenter equipped the subject's vehicle with a MnPass transponder to allow subjects to use the HOT lanes, and a logging Global Positioning System device (QSTARZ

\section{HOT Lanes@ @-394}

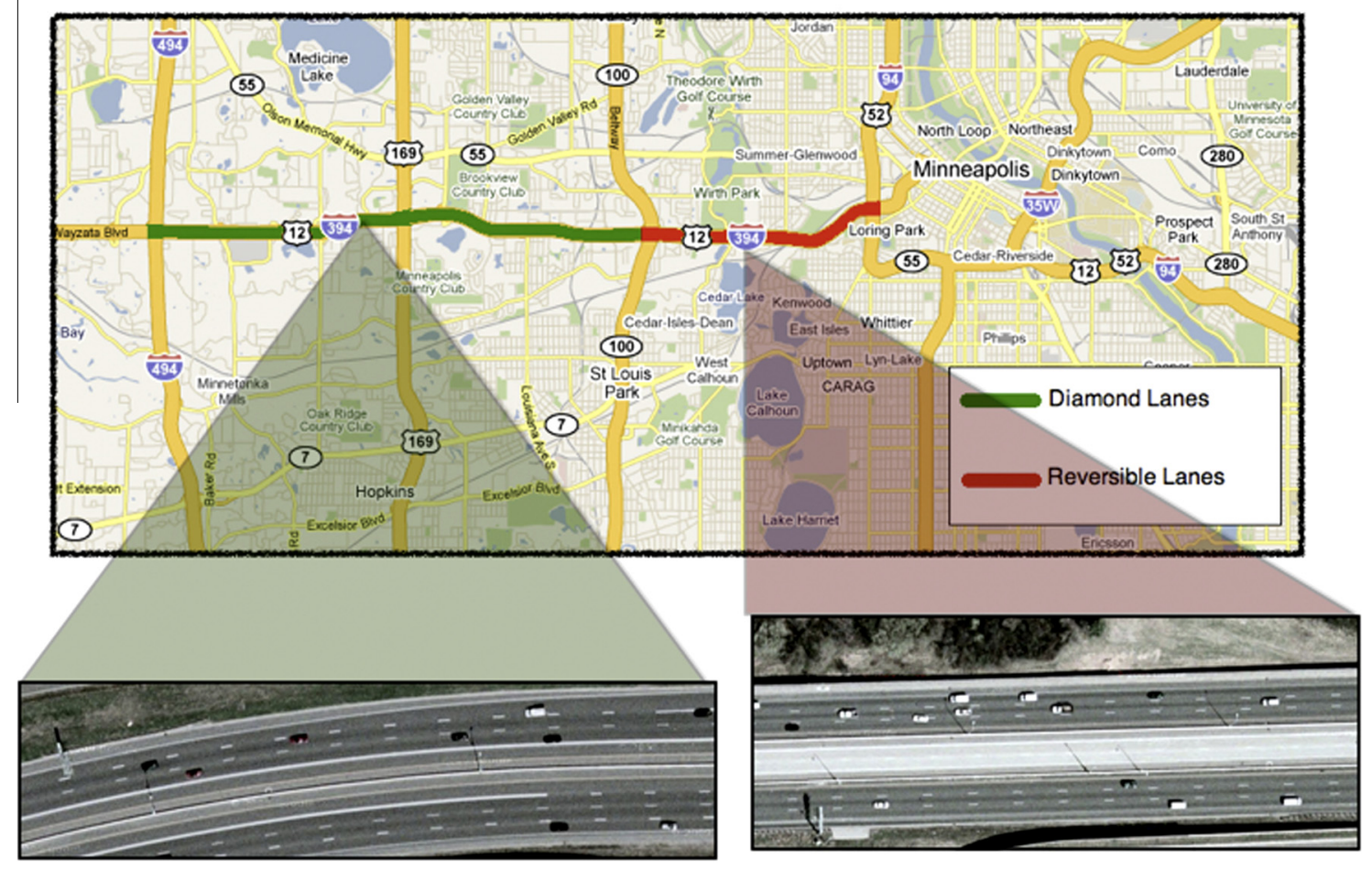

Fig. 1. Location of the I-394 High Occupancy Toll lanes. 
BT-Q1000p GPS Travel Recorder powered by DC output from in-vehicle cigarette lighter), in order to track their commute. None of the subjects owned a MnPass transponder before or during the study.

The recruited subjects receive instructions with regards to the routes they must use for their daily commutes. These routes can be grouped in five periods: an initial one to two week period of unrestricted travel (i.e. no route is assigned); a two week period of travel on an assigned signalized arterial close to the I-394 corridor (e.g. Hwy 55, Hwy 7); a two week period of travel on the general purpose lanes (untolled); a two week period of travel on the high-occupancy toll lanes (HOT; MnPass lanes); and a two week period of unrestricted travel on any of their three previous assigned routes (signalized arterial, general purpose lanes, and high-occupancy toll lanes). There are only 6 weeks between the weeks of unrestricted travel where the subjects are required to drive on their assigned routes (e.g. signalized arterial, HOT, GPL). In addition, subjects are provided with a MnPass transponder during their two week period of travel on the HOT lanes, and the last two weeks of travel (i.e. unrestricted travel on of the previous assigned routes). Furthermore, subjects were told that the only costs they will incur are the toll fees of using the HOT lanes during the last two weeks of travel. Thus, subjects knew that they will not pay the toll fees of two week period of required travel on the HOT lanes.

In the initial two weeks of travel, the subjects are allowed to choose freely, and thus a baseline travel choice can be established; the amount varies as installations were often done midweek, while the protocol for assigned routes began assigning routes on Mondays every two weeks. In the last two weeks of travel, the subjects were allowed to drive freely on any of their previous three assigned choices only, and were also provided with a MnPass transponder. The transponder is required in order to use the HOT lanes. In other words, each participant drove each of three assigned routes both in the morning and evening for two-week period (a total of 6 weeks between the weeks of unrestricted travel). The order of these routes was randomly assigned to each participant to control for effects of order. In this way, the subject's existing knowledge of alternative routes was augmented. This set a "before learning" route choice period (baseline travel choices; first week(s) of travel) vs. an "after learning" (travel choices after the random assignment of routes; last two weeks of travel) choice period as they selected among these routes freely only during the first week(s) and the last two weeks. Additionally, each of these routes provided reasonable and convenient ways of traveling between the subject's home and work. However, the exact routes as selected by the authors depended on each subject's home and work locations.

In Fig. 2, the set of signalized arterials used to provide an alternative route to each (besides I-394) subject is presented. The authors chose the closest signalized arterial to each of the subjects' home locations, and also that offers a close alternative to their work locations (near or in downtown Minneapolis).

Each week, the experimenter asked the subjects to complete a survey about their current daily route three times (Mondays, Wednesdays, and Fridays). This was done during 6 weeks to guarantee each of the alternative routes were reviewed by the subjects. In addition, at the end of the study period the subjects completed a final survey where they stated their final route choice preference. In this way, the degree of familiarity that the subjects already had with the alternate routes was determined. It should be noted that this degree may vary with the relative locations of each subject's home and work place. In addition, subject demographics (age, gender, income) and details of the drivers vehicle (make, model, and age of the vehicle) were collected. This was done to compare the sample of the study to the population in the Minneapolis-St. Paul metro area (see Section 4.2). However, the focus of this study is on the revealed preference data (i.e. route choices obtained from the GPS devices).

After the completion of the study period, the GPS receiver and MnPass Transponder were recovered from the subjects, and the GPS data extracted. The drivers were debriefed and fully compensated for their participation even though they believed that there was no reimbursement for using the MnPass transponder during their unrestricted choice period in the last two weeks of travel. The surveys and revealed preference (GPS and Transponder) data acquired from each of the participating drivers during the eight-week period was processed and employed to estimate the econometric route choice models in this study. It should also be noted that transponder data was augmented by a database of toll information detailed by the time, date and entrance station (points of access across the I-394 freeway to the HOT lanes). This database was provided by the Minnesota Department of Transportation (MnDOT) through MnPass.net. The original transponder data only provided toll information by time, date and entrance station when the subjects drove on the HOT lanes. The authors thanks to the database provided by MnPass.net are able to also see the toll of the HOT lanes even when the subjects chose untolled alternatives (signalized arterials and general purpose lanes), and also when the subjects chose the tolled alternative (MnPass transponder logs were confirmed with the database).

\subsubsection{Comparison to others techniques}

Generally, route choice studies can be divided according to the nature of the measured data (stated preference [SP] or revealed preference [RP]), and the data collection techniques employed (e.g. phone interviews). In Bovy and Stern (1990), two types of data sources for a route choice study are emphasized: (quasi) laboratory experiments, and field observations (i.e. actual trips). Furthermore, the most prominent data collection techniques are grouped under these two categories. Laboratory experiments include: paper-based experiments (e.g. multiple choice questions), experiments with visual aids (e.g. questions with charts, maps), and simulations (e.g. computer-based simulations, and fixed-base vehicle simulators). On the other hand, field observations include: interviews in person or through the phone; self-completion questionnaires; and stalking/shadowing the subjects (e.g. license plate matching). This last list can be expanded by including GPS tracking as a new item, or contained within stalking/shadowing the subjects. Although, it might not fit perfectly as the subjects are usually aware that their trips are being recorded. 

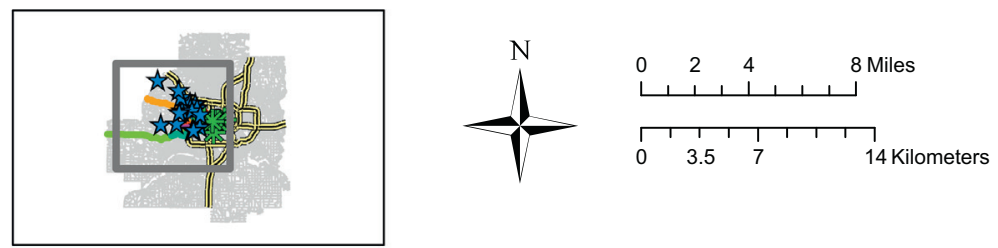

\section{neXus}

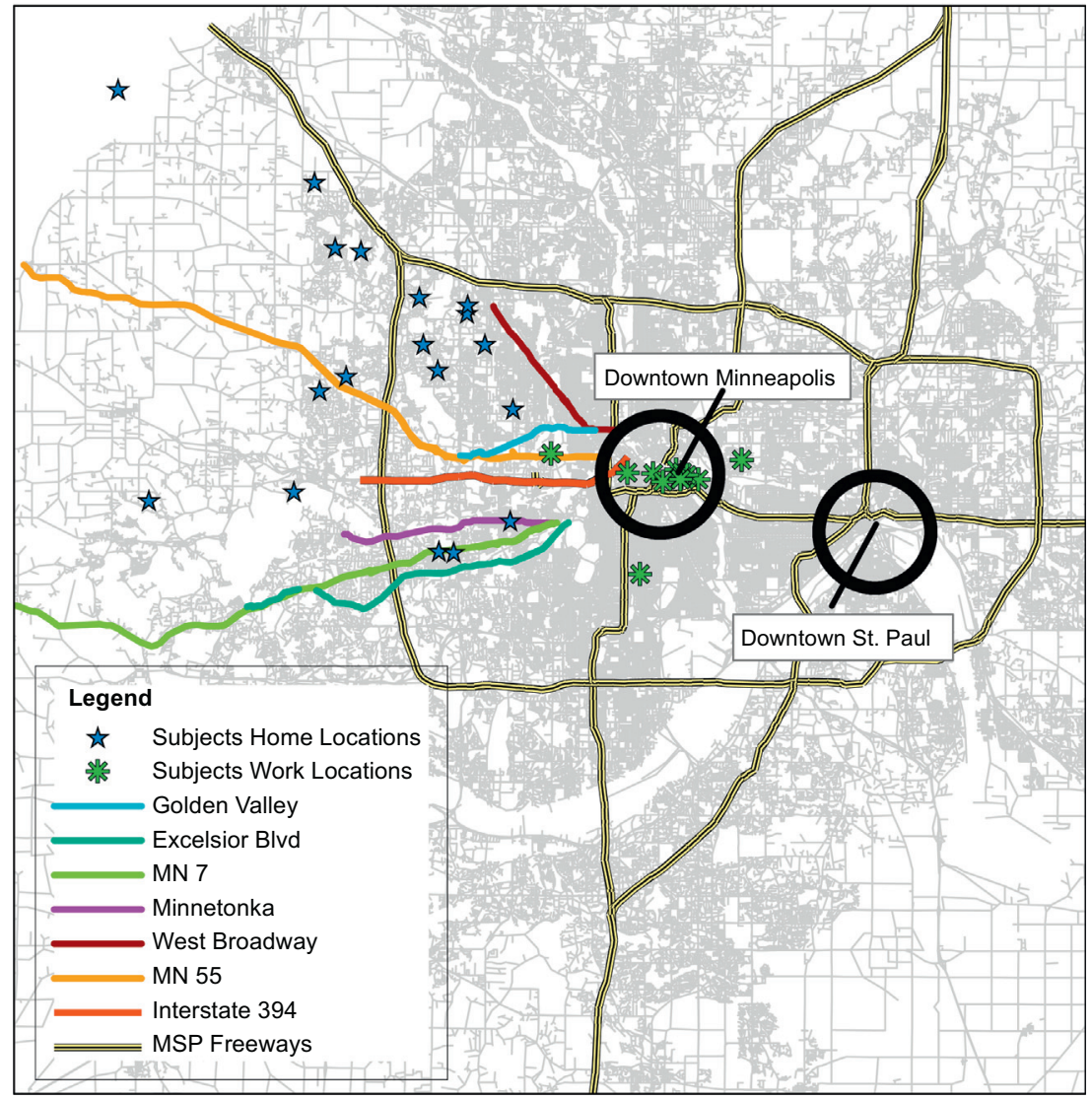

Fig. 2. Arterials considered for assignment to the subjects.

Both classes of data collection techniques (Laboratory and Field) have advantages and disadvantages. According to Bovy and Stern (1990), the main attributes that vary from technique to technique are: cost and resources; realism and validity; degree of control of the researcher over the experiment; researcher's ability to monitor the experiment; and degree of difficulty of separating a variable's effects from others. The first characteristic refers to the material, equipment, and labor costs. The second refers to how closely the experiment emulates a real route choice situation, and thus bring questions about its validity. The third and fourth refers to the level of management the researcher has over the elements in the experiment, and the ability to measure or collect data of variables during the experiment, respectively. The last refers to the level of complexity of the experiment due to a high number of factors interacting, and thus confounding any possible insights and/or statistical estimation. For these reasons, a researcher must consider the trade off he/she makes (e.g. lower cost but less realistic, actual route choices [RP] vs. hypothetical choices [SP]) when selecting a specific technique or more for their study.

In this research experiment, the authors use GPS tracking data along with questionnaires to gather information about each subject and their revealed preferred choice. This is also considering that each subject was randomly assigned to drive for two weeks on each route, and thus form their own opinions about each route (see Section 3 for more details). The authors refer to this experimental design as actual commute experience revealed preference (ACERP). This technique advantages include: real choices in an actual urban environment; subjects are familiarized with route alternatives; subject's origin (home) and destination (work) are preserved (i.e. not assigned); detailed objective measures of travel distance, travel time and other variables; and multiple records per route (panel data) in order to enrich the statistical analysis. However, this method has several disadvantages including: expensive as the cost of a GPS device increases if more features (e.g. wireless 
Table 3

Summary of data collection techniques in route choice studies.

\begin{tabular}{|c|c|c|c|}
\hline Method & $\begin{array}{l}\text { Data } \\
\text { type }\end{array}$ & Features & Examples \\
\hline $\begin{array}{l}\text { Questionnaires with } \\
\text { Hypothetical Scenarios }\end{array}$ & SP & $\begin{array}{l}\text { Controlled choice situations; Unrivaled freedom in defining } \\
\text { choice situations, alternatives, and variables; Automatic } \\
\text { format for fast data processing }\end{array}$ & $\begin{array}{l}\text { Jackson and Jucker (1982), Pal (2004), Abdel- } \\
\text { Aty et al. (1997), Tilahun and Levinson (2009), } \\
\text { and Khattak et al. (1993) }\end{array}$ \\
\hline $\begin{array}{l}\text { Questionnaires with } \\
\text { Hypothetical Scenarios } \\
\text { including visual aids }\end{array}$ & SP & $\begin{array}{l}\text { Inclusion of subjects unfamiliar to a specific analysis area; } \\
\text { Clear presentation of choices and variables }\end{array}$ & $\begin{array}{l}\text { Tilahun and Levinson (2010), Goldin and } \\
\text { Thorndyke (1982), and Bartram (1980) }\end{array}$ \\
\hline $\begin{array}{l}\text { Computer-based } \\
\text { simulator }\end{array}$ & SP & $\begin{array}{l}\text { Interactive systems under controlled choice situations; } \\
\text { Flexible and dynamic regulation of subject's interaction with } \\
\text { the environment }\end{array}$ & $\begin{array}{l}\text { Mahmassani and Herman (1989) and Leiser } \\
\text { and Stern (1988) }\end{array}$ \\
\hline $\begin{array}{l}\text { Fixed-base vehicle } \\
\text { simulators }\end{array}$ & SP & $\begin{array}{l}\text { Dynamic virtual environments with colors, perspectives, and } \\
\text { image combinations; Simulation of weather and light } \\
\text { conditions }\end{array}$ & $\begin{array}{l}\text { Blaauw (1982), Scott (1985), and Godley et al. } \\
\text { (2002) }\end{array}$ \\
\hline $\begin{array}{l}\text { Virtual Experience Stated } \\
\text { Preference (VESP) }\end{array}$ & $\mathrm{SP}$ & $\begin{array}{l}\text { Physical Simulators are used to generate dynamic } \\
\text { environments; Subjects are monitored during the } \\
\text { experiment; Subjects follow several scenarios assigned by the } \\
\text { researcher }\end{array}$ & Levinson et al. (2004) and Levinson et al. (2006) \\
\hline $\begin{array}{l}\text { Field Experience Stated } \\
\text { Preference (FESP) }\end{array}$ & SP & $\begin{array}{l}\text { GPS devices are used in subjects' vehicles; Subjects' routes } \\
\text { and origin-destination pair are assigned by the researcher. }\end{array}$ & Zhang and Levinson (2008) \\
\hline $\begin{array}{l}\text { Field Self-Completion } \\
\text { Questionnaires }\end{array}$ & $\mathrm{RP}$ & $\begin{array}{l}\text { Maps and images help the subjects mark their preferred } \\
\text { routes }\end{array}$ & $\begin{array}{l}\text { D'Este (1986) and Duffell and Kalombaris } \\
\text { (1988) }\end{array}$ \\
\hline Field interviews & $\mathrm{RP}$ & $\begin{array}{l}\text { Subjects report choices through the phone or in-person; } \\
\text { Information about perception can be extracted }\end{array}$ & Small et al. (2005) and Small et al. (2006) \\
\hline Stalking/shadowing & $\mathrm{RP}$ & $\begin{array}{l}\text { Subjects are followed stealthily in order to determine their } \\
\text { preferred routes }\end{array}$ & Chang and Herman (1978) \\
\hline Field GPS Tracking & $\mathrm{RP}$ & $\begin{array}{l}\text { GPS devices are used to track very detailed trip data for each } \\
\text { subject }\end{array}$ & Li et al. (2004), Li et al. (2005), and Li (2004) \\
\hline $\begin{array}{l}\text { Actual Commute } \\
\quad \text { Experience Revealed } \\
\text { Preference (ACERP) }\end{array}$ & $\mathrm{RP}$ & See Section 3 & \\
\hline
\end{tabular}

communication) are required (this study used logging GPS, avoiding communications cost, but limiting ability to gather real-time information from subjects); subjects might dislike having to drive the same unpreferred route for two weeks, especially if the route requires them to adjust their departure time; and additional funds need to be allocated in order to reduce attrition rate in the experiment.

A summary of selected studies for each mentioned data collecting technique is presented in Table 3.

\section{Data}

\subsection{Recruitment}

The subjects for this experiment were recruited through the use of distinct tools including: Craigslist.org, and CityPages.com; the free local weekly newspaper City Pages; flyers at grocery stores; flyers at city libraries, postcards handed out in downtown parking ramps; flyers placed in downtown parking ramps; and emails to more than 7000 University of Minnesota staff (students and faculty were excluded).

The recruitment process was repeated a total of three times. The first sample was selected in August 2008; the second in March 2009; and the third in September 2009. A total pool for the three recruitment attempts was of about 223 possible candidates. These possible recruits had to satisfy the following requirements in order to be part of the experiment:

1. Age between 25 and 65 .

2. Daily commutes of at least $20 \mathrm{~min}$.

3. Likelihood of using Interstate 394 for their commutes.

4. At least four regular work days per week.

5. Work location near or in downtown Minneapolis.

6. Single occupancy vehicle travelers.

7. Permission to install a GPS device in the vehicle.

8. Vehicle must allow continuous power supply to GPS device.

These criteria were developed to select a representative sample from the drivers using I-394 in the Twin Cities area. There are two reasons that participants were selected with 20 min commutes. First, they are likely to have more alternatives. Second, the statistical estimation will improve if the participants' commute distances are similar. In addition, I-394 must 
Table 4

Socio-demographics attributes of the sample.

\begin{tabular}{|c|c|c|c|}
\hline \multirow[t]{2}{*}{ Number of subjects } & & \multicolumn{2}{|l|}{18} \\
\hline & & Sample & Twin cities \\
\hline \multirow[t]{2}{*}{ Sex } & Male & $39.89 \%$ & $49.40 \%$ \\
\hline & Female & $61.11 \%$ & $50.60 \%$ \\
\hline \multirow{6}{*}{$\begin{array}{l}\text { Age (mean, std. deviation) } \\
\text { Education }\end{array}$} & & $(52,10)$ & $(34.47,20.9)$ \\
\hline & 11th Grade or less & $0.00 \%$ & $9.40 \%$ \\
\hline & High school & $11.11 \%$ & $49.60 \%$ \\
\hline & Associate & $27.78 \%$ & $7.70 \%$ \\
\hline & Bachelors & $44.44 \%$ & $23.20 \%$ \\
\hline & Graduate or professional & $16.67 \%$ & $10.10 \%$ \\
\hline \multirow[t]{5}{*}{ Household income } & $\$ 49,999$ or less & $22.22 \%$ & $45.20 \%$ \\
\hline & $\$ 50,000$ to $\$ 74,999$ & $27.78 \%$ & $23.30 \%$ \\
\hline & $\$ 75,000$ to $\$ 99,999$ & $11.11 \%$ & $14.60 \%$ \\
\hline & $\$ 100,000$ to $\$ 149,999$ & $27.78 \%$ & $11.00 \%$ \\
\hline & $\$ 150,000$ or more & $11.11 \%$ & $5.90 \%$ \\
\hline \multirow{3}{*}{ ( } & Black/African American & $11.11 \%$ & $6.20 \%$ \\
\hline & White or Caucasian & $88.89 \%$ & $87.70 \%$ \\
\hline & Others & $0.00 \%$ & $6.10 \%$ \\
\hline Years at current work (mean, std. deviation) & & $(13.86,11.12)$ & \\
\hline Years at current home (mean, std. deviation) & & $(9.83,7.93)$ & \\
\hline
\end{tabular}

Note: Minneapolis' Population statistics are obtained from the American Community Survey (2009).

be a likely route for the participants, because it is doubtful any participant will participate in (or remain with) the study if they have to stray too far from their regular routes. Furthermore, participants needed to have simple commuting patterns, because more complicated patterns (chained trips) would have been a confounding factor in the study. Other factors like non-home/non-work destinations might have played the central role in the route choice process. Also, participants must travel alone (single occupancy vehicle travelers) to avoid route choice decisions (e.g. toll free usage of HOT lanes for carpoolers) influenced by car passengers. Lastly, participants must allow installation of GPS devices; these devices require continuous power supply power to function properly.

A total of 54 participants were recruited for the study. Only 18 finished due to a high dropout rate (25 participants left the study) and unfortunate GPS equipment failure (11 participants' data were lost). Each of the participants that completed the study successfully (followed instructions as described by the experimenter) was given compensation of USD \$125.00. The sample issues are discussed further in Section 5.

\subsection{Descriptive statistics}

Table 4, summarizes socio-demographic information of the subjects. Main difference of the sample vs. the population of the Twin cities include: higher proportion of females; and subjects are on average older, more educated, and have higher income. Other characteristic of the sample is the variation of the subjects' time living at their current work and home location is high. In other words, the sample has subjects ranging from those living several years in their current work and/or home locations to those living a few months in their current work and/or home locations.

\subsection{Data processing}

The raw data generated by the GPS device consisted of a list of codes with detailed trip information including: record ID, latitude and longitude, date and time, and instantaneous speed. Each of the codes represent one point per $25 \mathrm{~m}$ in the travel trajectories of each vehicle. In ideal conditions, the displacement of the vehicles are accurately captured by the GPS. In some situations, the records are not accurate, because it might take the GPS device a few minutes to initialize after the vehicle's engine is on. These points were excluded from the dataset. In addition, out-of-town trips during holidays (e.g. Thanksgiving) were also excluded. The actual routes used for the analysis were built by merging these points with a Geographic Information System (GIS) map. This map is referred to as the TLG network, which is maintained by the Metropolitan Council and The Lawrence Group (TLG). It covers the entire 7-county Twin Cities Metropolitan Area and is the most accurate GIS map of this network to date. The TLG network contains 290,231 links, and provides an accurate depiction of the entire Twin Cities network at the street level. Twenty-meter buffers are used for all roads, in order clip the GPS records. All points outside of Twin Cities area as well as off-road points were excluded. The remaining points were regrouped into trips; these trips contained all points between one engine-on and engine-off events for each subject. In this way, all trips by each subject were identified along with the characteristics of each trip, including the starting time, the ending time, the path used, and travel speed on each link segment along the route. Another process (or algorithm) was also developed in order to determine the commute trips for each subject, and identify each of the routes (e.g. I-394) followed by each trip. The algorithm worked by matching trips origins to home location, and trip destinations to work location, and vice versa. The distance tolerance between origins 


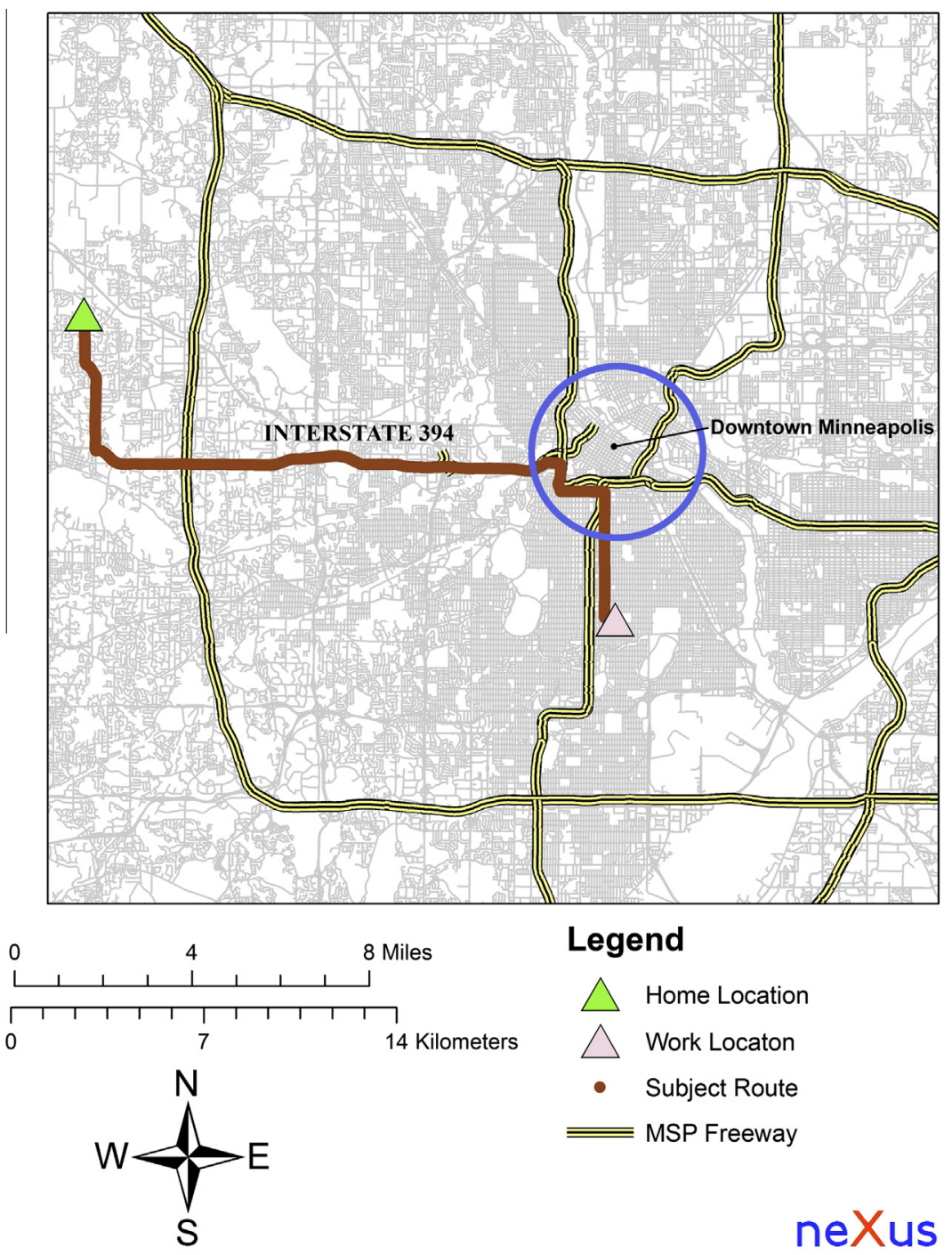

Fig. 3. Example of a subject's commute trip using I-394.

(destinations) to home (work) locations was set to 600 meters. In addition, a threshold was set for the start of a new trip at 5 min. This temporal constraint guarantees that the trips are mostly direct, and avoids confounding difficulties such as chained trips. This complete process was done inside the ArcGIS environment. An example can be seen in Fig. 3.

\section{Issues with subjects and technology}

\subsection{Subjects: recruitment and retention}

The main issues in the study were subject recruitment and subject retention. In the case of recruitment, the difficulty was finding enough subjects that allowed for a larger sample. A possible reason was the restrictive selection criteria; although a total of about 223 possible candidates applied, only 54 satisfied the requirements. Unfortunately, these restrictions could not be lifted as subjects with stable commutes (e.g. at least four days of work), likelihood of using I-394, and GPS devices installed inside their vehicles were indispensable conditions. In addition, three possible candidates reported they were interested in participating if the compensation of USD\$125 was higher. This leads to the possibility that higher compensation could have helped to increase our sample size. However, additional recruiting efforts were done to obtain a larger overall sample size.

In the case of retention, the nature of the experimental design seemed to disenchant some of the participants. Three classes of subjects left the study. The first one occurred when a subject was required to use a customized arterial route (selected 
according to home and work location). Initially, subjects drove it without complaining, but later during the same week or the next week, they withdrew from the study giving reasons such as: travel-time was too high; route was highly inconvenient; resistance to using arterial routes; and many others. The second one occurred when a subject was required to use the I-394 (general purpose lanes or HOT lanes). For this path, subjects withdrew immediately usually within two days. Their reasons for leaving included: lack of accessibility to desired commercial zones; and other perceived benefits of using the arterial over the freeway. The third one included miscellaneous cases with distinct reasons such as: vehicular accident; vehicle stolen; death of a family member; injury of participant requiring hospitalization; vehicle requiring prolonged stay at the mechanic; and many others. Unfortunately, the information we have of the subjects that left is anecdotal and it was summarized from communication between the authors and the subjects.

\subsection{Technology: data failure}

The GPS device became an additional issue for the study. For some of the subjects, the device did not collect complete experimental data (none or only a fraction of the study period were retrieved). These devices were sent to QSTARZ for analysis, and more importantly to recover the lost data. Fortunately, the QSTARZ team was able to extract data from some of the devices. In addition, the QSTARZ team performed several tests to determine the underlying cause of the GPS device failure while it was deployed in the field. However, they did not find conclusive evidence for failure to be attributed solely to the equipment itself. Another possibility for the failure of the device could be attributed to subjects unplugging the equipment. This GPS device requires continuous power supply from the vehicle's battery in order to function properly. Therefore, if the device is unplugged for long periods, it will cease logging data, and in the worst case it will require resetting to log data again (this method clears the memory). Unfortunately, the experimenter was unable to know when exactly the device stopped working. For this, the experimenter requires more expensive equipment, with permanent or semi-permanent installation, that allows day-to-day monitoring.

In the end, the Table 1 shows the number of participants who fulfilled the study's criteria (denoted as initial subjects), the participants who left study, GPS data failure, and remaining subjects.

\section{Econometric model: specification and estimation}

\subsection{Specification}

The GPS data (travel time measures and revealed preferences) along with socio-demographic information from surveys are analyzed through a random utility model (RUM; see Ortuzar and Willumsen (2011), Ben-Akiva and Lerman (1985), and Train (2009)). Three systematic utility functions are specified for the choice situation according to the proposed experimental design (Arterial vs. GPL vs. HOT). Furthermore a linear-in-parameters functional form is used for the systematic utility functions.

The data set is composed of the last two weeks of "free travel" (unrestricted travel; see Section 3.1.2) for the subjects' choices (revealed preferences). These choices are only composed of direct commute trips (see Section 4.3). Therefore, a subject's route choice (Arterial vs. GPL vs. HOT) for its commute (home to work, and also work to home) for a given day (of his/ her last two weeks of "free travel") corresponds to his/hers choice for that occasion (i.e. choice situation). In total, it is expected that each subject (18 subjects) will perform 2 commute trips per day for 10 days ( 2 weeks). This leads to the upper bound of 360 occasions of choice for the 18 subjects, and 20 occasions of choice for each subject. Thus, the data set will be a balanced panel data (same number of repeated observations for each subject across commute trips in different days). However, this is not the case (data set is an unbalanced panel) as subjects may forego certain commute trips on some days, or may choose to chain activities for their trips (only direct commute trips are considered). The number of observations per subject varies between a minimum of only 5 commute trips to a maximum of 23 commute trips (i.e. some subjects returned their devices a few days after their last two weeks of "free travel" ended). The average number of observations per subject is 12.2 commute trips. Total number of observations is 219 for 18 subjects. Furthermore, the variation of choices across trips (i.e. choice situations) per subject is summarized in Table 7. This table indicates that most of the subjects distributed their (direct) commute trips across two or three of the alternatives. Only two subjects concentrated their (direct) commute trips on one alternative.

The analysis of panel data such as this one (repeated observations per subject for distinct days) requires a model that handles explicitly the individual-specific variation (or unobserved/unmeasured heterogeneity) and the state dependency (or habit formation/variety seeking behavior). Hsiao (2003) (in Chapter 7) discusses and recommends several parametric approaches to model the heterogeneity while accounting for the state dependency. In this study, a parametric method of random coefficient (for the travel time variables) and lagged variables (including terms accounting for previous choices) is adopted. The assumption is that subjects may differ in the individual-specific variation with regards to the effects of travel time (both its centrality and dispersion measures) in their commute, and also subjects may be influenced by previous choices (inertia to try new routes, or a variety seeking behavior of trying different routes). In essence, a dynamic choice model is adopted (Hsiao, 2003; Train, 2009; Ortuzar and Willumsen, 2011). 
Table 5

Correlations between travel time-based variables across the 18 subjects.

\begin{tabular}{lllll}
\hline Travel time measures & Mean & Median & Std. deviation & Right range \\
\hline Mean & 1.0000 & & & \\
Median & 0.9589 & 1.0000 & 1.0000 & 1.0000 \\
Std. deviation & 0.3105 & 0.2368 & 0.9472 & 0.9130 \\
Right range & 0.3295 & 0.2095 & 0.9007 & 1.0000 \\
Interquartile range & 0.3413 & 0.2507 & \\
\hline
\end{tabular}

Table 6

Summary statistics of travel time and tolls across the 18 subjects.

\begin{tabular}{|c|c|c|c|c|c|}
\hline & & Arterial (min) & GPL (min) & HOTL (min) & Toll (\$USD) \\
\hline \multirow[t]{5}{*}{ Monday } & Mean & 32.10 & 32.84 & 30.20 & 0.93 \\
\hline & Median & 32.09 & 31.20 & 28.81 & 0.80 \\
\hline & Std. Dev. & 7.86 & 8.74 & 6.58 & 0.66 \\
\hline & Right Rng. & 8.03 & 9.58 & 8.02 & 1.08 \\
\hline & Interquartile Rng. & 7.24 & 9.19 & 6.56 & 0.91 \\
\hline \multirow[t]{5}{*}{ Tuesday } & Mean & 34.27 & 35.84 & 34.60 & 0.87 \\
\hline & Median & 33.87 & 33.33 & 34.14 & 0.46 \\
\hline & Std. Dev. & 11.77 & 10.39 & 8.98 & 0.78 \\
\hline & Right Rng. & 14.19 & 12.13 & 8.13 & 1.89 \\
\hline & Interquartile Rng. & 11.58 & 8.76 & 7.70 & 0.89 \\
\hline \multirow[t]{5}{*}{ Wednesday } & Mean & 33.74 & 35.58 & 30.43 & 0.70 \\
\hline & Median & 33.36 & 33.09 & 29.04 & 0.48 \\
\hline & Std. Dev. & 5.75 & 7.98 & 8.00 & 0.63 \\
\hline & Right Rng. & 5.45 & 10.05 & 8.99 & 1.42 \\
\hline & Interquartile Rng. & 6.03 & 9.48 & 7.02 & 0.82 \\
\hline \multirow[t]{5}{*}{ Thursday } & Mean & 34.91 & 36.27 & 30.77 & 0.85 \\
\hline & Median & 33.81 & 33.91 & 29.15 & 0.67 \\
\hline & Std. Dev. & 7.20 & 10.09 & 8.66 & 0.65 \\
\hline & Right Rng. & 8.01 & 11.52 & 10.40 & 1.12 \\
\hline & Interquartile Rng. & 7.56 & 9.63 & 7.96 & 1.04 \\
\hline \multirow[t]{5}{*}{ Friday } & Mean & 33.42 & 35.02 & 31.20 & 0.62 \\
\hline & Median & 32.99 & 33.25 & 29.34 & 0.51 \\
\hline & Std. Dev. & 8.21 & 8.08 & 7.25 & 0.49 \\
\hline & Right Rng. & 7.90 & 9.30 & 8.74 & 0.72 \\
\hline & Interquartile Rng. & 7.26 & 9.09 & 7.39 & 0.70 \\
\hline
\end{tabular}

Table 7

Percentage of the subjects' choices for the last two weeks of unrestricted travel.

\begin{tabular}{|c|c|c|c|c|}
\hline Subject ID & HOT (\%) & GPL (\%) & Arterial (\%) & Total trips ${ }^{\mathrm{a}}$ \\
\hline Subject 1 & 7.69 & 61.54 & 30.77 & 13 \\
\hline Subject 2 & 4.76 & 33.33 & 61.90 & 21 \\
\hline Subject 3 & 9.09 & 45.45 & 45.45 & 11 \\
\hline Subject 4 & 0.00 & 28.57 & 71.43 & 7 \\
\hline Subject 5 & 0.00 & 25 & 75 & 16 \\
\hline Subject 6 & 0.00 & 0.00 & 100.00 & 5 \\
\hline Subject 7 & 0.00 & 90.91 & 9.09 & 11 \\
\hline Subject 8 & 27.27 & 0.00 & 72.73 & 11 \\
\hline Subject 9 & 0.00 & 4.35 & 95.65 & 23 \\
\hline Subject 10 & 7.14 & 64.29 & 28.57 & 14 \\
\hline Subject 11 & 10.00 & 10.00 & 80.00 & 10 \\
\hline Subject 12 & 0.00 & 63.64 & 36.36 & 11 \\
\hline Subject 13 & 0.00 & 10.00 & 90.00 & 10 \\
\hline Subject 14 & 0.00 & 83.33 & 16.67 & 12 \\
\hline Subject 15 & 0.00 & 63.64 & 36.36 & 11 \\
\hline Subject 16 & 12.50 & 62.50 & 25.00 & 16 \\
\hline Subject 17 & 0.00 & 40.00 & 60.00 & 10 \\
\hline Subject 18 & 0.00 & 0.00 & 100.00 & 7 \\
\hline
\end{tabular}

a This includes trips in the morning, and trips in the afternoon. 
The required specification (accounting for both unobserved heterogeneity and state dependency) can be formulated in a mixed multinomial logit model (Hsiao, 2003; Train, 2009; Ortuzar and Willumsen, 2011). Assume that the utility function a decision-maker $k$ in the set of decision-makers $\mathcal{N}$ associates with alternative $j$ in the set of choices $\mathcal{C}$ for a given choice situation $t$ in the set of choice situations $\mathcal{T}$ is given by:

$$
\begin{aligned}
U_{j t}^{k} & =V_{j t}^{k}+\xi_{j t}^{k} \\
U_{j t}^{k} & =V_{j t}^{k}+\left[\eta_{j t}^{k}+\epsilon_{j t}^{k}\right] \\
U_{j t}^{k} & =\beta^{T} x_{j t}^{k}+\alpha^{T} z_{j t, t-1, \ldots t_{0}}^{k}+\left[\left(\rho^{k}\right)^{T} x_{j t}^{k}+\left(\gamma^{k}\right)^{T} z_{j t, t-1, \ldots t_{0}}^{k}+\epsilon_{j t}^{k}\right]
\end{aligned}
$$

In the Eq. (1), $V_{j t}^{k}$ is the systematic utility, and $\xi_{j t}^{k}$ is the unsystematic utility (or error term). This is the standard functional form for any random utility model. For this case of mixed logit model, the functional form is given by Eq. (2), and more explicitly by Eq. (3). The random term is partitioned into three additive parts: The first $\left(\rho^{k}\right)$ is an individual-specific random vector distributed as a multivariate normal density function (with zero mean vector, and 0 off-diagonal elements for the covariance matrix $\Sigma$ ) over decision-makers. The second $\left(\gamma^{k}\right)$ is a random vector distributed as the previous one but corresponds to the state dependent variable in the regressors' matrix.The third $\left(\epsilon_{j t}^{k}\right)$ is a random vector identically and independently distributed (i.i.d.) over choice situations, alternatives and decision-makers following an extreme value type 1 (or Gumbel) distribution. Furthermore, the systematic utility $\left(V_{j t}^{k}\right)$ is linear in the parameters, and it is decomposed into: alternative-specific and alternative-invariant explanatory variables ( $\beta^{T} x_{j t}^{k}$; includes toll costs, socio-demographic, and the means of the random coefficient variables [travel time measures]); and the state dependent variables ( $\alpha^{T} z_{j t, t-1, \ldots . t_{0}}^{k}$; includes variables accounting for habit formation and variety seeking behavior). This econometric specification is based on the model specification structure of Johannesson and Lundin (2002). It should be noted that the correlation over alternatives and choice situations is explicitly accounted by a part $\left(\eta_{j t}^{k}\right)$ of the combined error term $\left(\xi_{j t}^{k}\right)$, and a part of the combined error term $\left(\xi_{j t}^{k}\right)$ is still independent $\left(\epsilon_{j t}^{k}\right)$. Readers can refer to Johannesson and Lundin (2002) for more details of the model specification structure.

The likelihood for this mixed logit model is given by:

$$
L(\beta, \alpha, \Sigma)=\prod_{\forall k \in \mathcal{N}} \int_{-\infty}^{\infty} \prod_{\forall t \in \mathcal{T}} \prod_{\forall j \in \mathcal{J}}\left(\frac{e^{V_{j t}^{k}(\beta, \alpha)}}{\sum_{j=1}^{J} e^{V_{j t}^{k}(\beta, \alpha)}}\right)^{\delta_{k j t}} f\left(\eta^{k} \mid 0, \Sigma\right) d \eta^{k}
$$

where the $\delta_{k j t}$ variable is one for the chosen $j$ alternative of the $k$ decision-maker for choice situation $t$, and zero otherwise. The function $f\left(\eta^{k} \mid 0, \Sigma\right)$ represents the multivariate normal density with zero mean vector, and covariance matrix $(\Sigma)$. Furthermore, the estimation of the parameters (coefficients and diagonal elements of the covariance matrix $\Sigma$ ) in this model is done using a user-written module in the STATA statistical package (Hole, 2007b). This module uses the Maximum Simulated Likelihood estimator with Halton draws as described in Train (2009). In this study, 250 Halton draws are employed.

The explanatory variables considered for the systematic utilities are based on travel time measures, travel cost, and sociodemographic factors. Furthermore, the general form of the additive linear in parameters systematic utility is:

$$
V_{j t}^{k}(\beta, \alpha)=f\left(T_{j t}^{k}, V_{j t}^{k}, C_{j t}^{k}, S^{k}, H_{j t}^{k}, D_{t}^{k}, A_{j}\right)
$$

where

- T: Centrality measure of travel time (varies by alternative, individual and choice situation)

- V: Dispersion measure of travel time (varies by alternative, individual and choice situation)

- C: Toll cost (varies by alternative, individual and choice situation)

- S: Socio-demographic (varies by individual)

- H: Habit/Variety Seeking (varies by alternative, individual and choice situation)

- D: Time of day (varies by individual and choice situation)

- A: Alternative specific constants (ASCs)

\subsubsection{Centrality measures, and dispersion measures of travel time}

Intrapersonal travel time distributions are available (from the GPS data) for each subject for the days of the week (e.g. Monday, Tuesday) of their choice situations. In other words, travel times of the trips (i.e. the whole trip) for a specific route (e.g. Arterial) can be grouped by days of the week in order to form a intrapersonal (it only uses travel times specific to each subject) travel time distribution per route per day of the week of the choice situations. These travel times of the subjects' trips are obtained from the route assignment weeks ( 6 weeks period), and the weeks of "free travel" (i.e. unrestricted travel) of each subject (see Section 3.1.2). In essence, each choice situation (of a subject) occurs on a specific day of the week (e.g. Monday), and thus the travel times of previous trips (matching the route of the choice situation), and the current choice situation trip can be used to form travel time distributions.

For each of subjects' travel time distributions for each day of the week of an occasion of choice (i.e. choice situation), centrality and dispersion measures can be calculated. For the centrality measure, the mean and the median are considered. For 
the dispersion measure, distinct measures have been theorized and developed in order to establish a more direct connection between travel time variability (i.e. dispersion or spread of a travel time distribution) and travel time unreliability, and consequently measure the latter accurately.

Based on Tilahun and Levinson (2010), three travel time unreliability measures are explored:

- Standard deviation (SD): a classical measure in the research literature. A model estimated with this measure is useful for comparison purposes, as it is a commonly found among travel time reliability studies.

- Shortened right range of the travel time distribution (90th-50th percentile) [RR], typically found in departure time choice models.

- Interquartile range of the travel time distribution (75th-25th percentile) [IQR].

The different formulations offer insight into how each unreliability variable is traded off in decision making with travel time and travel cost. The first considers that decisions are motivated by avoiding the overall travel time variability without differentiating the value decision-makers might place on lateness vs. earliness. The second considers that decisions are motivated by extreme values of the right range, which should translate to values decision-makers place solely on lateness. The third consider that decisions are motivated by avoiding the overall travel time variability (without regards to the extremes) as denoted by the interquartile range.

The correlations of travel time measures for all subjects are presented in Table 5 . The correlation between the centrality measures (mean and median) and the dispersion measures (standard deviation, shortened right range, and interquartile range) is not high in contrast to the correlation within centrality measures, and within dispersion measures. The reason is that the correlation is calculated across the measures (i.e. mean, standard deviation) of different intrapersonal travel time distributions. In other words, some subjects may have higher travel times for some routes, but low variability as the travel times are "stable". Thus, the correlation of centrality and dispersion measures within subjects may vary.

The average of the centrality and dispersion measures (of each of subjects' intrapersonal travel time distributions) for all subjects are presented in Table 6. The table indicates that on average (for all subjects) the HOT lanes (or MnPass lanes) have smaller travel times and less variable travel times in comparison to the other alternatives (GPL, and Arterials). In addition, on average the GP lanes and Arterials are not so dissimilar in terms their travel time, and their variability. It should be remembered that the travel time savings and/or reliability improvements (a route's smaller variability with respect to another) of GP lanes and/or Arterials over HOT lanes may exist for certain situations (or occasions) of choice of some subjects.

These variables are measured in minutes.

6.1.2. Toll cost

A database was provided to the authors by the Minnesota Department of Transportation (MnDOT) through MnPass.net. The database includes toll information of Minnesota's I-394 from August 2008 to December 2009. The database contains: value of tolls for specific dates, times (the resolution is to the minute), and entrance stations (i.e. access points to the HOT). In addition, subjects' MnPass transponder logs (also provides information of tolls, date and time but only when a subject uses the HOT lanes) were confirmed with the database. Furthermore, the database provides toll information of the HOT lanes even when the subjects chose untolled alternatives (signalized arterials and general purpose lanes), and also when the subjects chose the tolled alternative.

This variable indicates the toll that would have been paid by subjects at a specific choice situation for the I-394 HOT lanes. It is measured in current US Dollars.

\subsubsection{Socio-demographic}

These are a set of variables describing the attributes of each of the subjects. In this study, one variable was specified: Male ( 1 = male, 0 = female), and it was interacted with the travel time variability variable (i.e. dispersion measure of travel time).

\subsubsection{Habit/variety seeking}

In this study, a one period lagged variable is adopted. The approach consist of including a variable that accounts for the previous usage of a specific route choice (e.g. GPL) to an alternative as an attribute. A positive coefficient on this attribute for an alternative translates into an increase in the probability of choosing that particular alternative. In contrast a negative coefficient implies that the probability of choosing that particular alternative decreases. Thus, habits (or inertia) for a particular alternative could be argued to be represented by a positive coefficient, and variety seeking behavior by a negative coefficient for a particular alternative.

\subsubsection{Time of day}

An alternative-invariant dummy variable indicating whether the trip was done between 12:00 AM to 11:59 AM (0= PM) or 12 PM to 11:59 PM (1 = PM). This variable is included only in the GPL and HOT alternatives.

\subsubsection{Alternative specific constants (ASCS)}

These variables are specified to each alternative. For identification purposes, the alternative specific constant of the arterial choice is set to 0 . 


\subsection{Valuation of travel time: savings and reliability}

Recently, the coefficients of the travel time measures are considered to be stochastic in random utility models, because it is hypothesized that travelers may have distinct responses to their perception of time (both travel time, and its variability). For example, these responses can be explained by assuming that travelers possess different risk-taking behaviors (averse, neutral, or prone). Risk averse and risk prone travelers consider the variance and expectation of the perceived travel time in their choice process. The former (latter) exhibits preferences for low (high) variability, and it analyzes its trade off with the expected travel time. Risk neutral travelers are indifferent to travel time variability. Other reasons might also include flexible work entry time, and consequently travelers not feeling pressured to be at their jobs on a specific time. These traveler constraints and others are unknown to the researcher, and thus end up being neglected in the models' systematic utility. Unfortunately, these unobserved preferences are typical in disaggregate microeconomic data as Cameron and Trivedi (2005) points out. Moreover, multivariate normal density functions (with 0 off-diagonal elements in the covariance matrix) were selected as the probability density distribution (or population distribution as it is referred) of the coefficients. The reason for selecting this distribution instead of others (e.g. lognormal) is because the normal distribution performance was adequate despite the potential of yielding values of coefficients that might be theoretically unsound (e.g. positive travel cost; Hess et al. (2005)). Other distributions considered include the log-normal and the truncated normal. The log-normal distribution was disregarded because it tends to yield very high values of the coefficients that are likely to be improbable, and more importantly, we were not able to estimate (achieve convergence) in most of our models. The truncated normal distribution was also disregarded, because it is difficult to tell whether the parameter values (and its associated calculated valuation measures such as VOT) were biased by the selection of the bounds. Finally, this analysis chooses to keep cost as a fixed parameter for calculating valuation measures (e.g. VOT) in order to avoid the problems associated with taking ratio of random variables (Sillano and Ortuzar, 2005). Readers are referred to Sillano and Ortuzar (2005), Orro-Arcay (2005), and Hess (2005) for more details.

Generally, marginal rates of substitution (i.e. willingness-to-pay measures) between travel time measures ( $T$ for a centrality measure, and $R$ for dispersion measure) and the toll cost $(C)$ may be computed from the proposed econometric model in order to obtain the quantities of study such as the value of travel time savings (VOT), the value of travel time reliability (VOR), and the reliability ratio (RR). These are defined formally as follows,

$$
\begin{aligned}
& V O T=\frac{\partial U_{j}^{k} / \partial T_{j}^{k}}{\partial U_{j}^{k} / \partial C_{j}^{k}} \\
& V O R=\frac{\partial U_{j}^{k} / \partial R_{j}^{k}}{\partial U_{j}^{k} / \partial C_{j}^{k}} \\
& R R=\frac{\partial U_{j}^{k} / \partial R_{j}^{k}}{\partial U_{j}^{k} / \partial T_{j}^{k}}=\frac{V O R}{V O T}
\end{aligned}
$$

In this study, six models (following the previous econometric specification) are considered: Mean/SD, Mean/RR, Mean/IQR, Median/SD, Median/RR and Median/IQR. The model name refers to the centrality and the dispersion measures used in its systematic utility. In this way, VOT, VOR and RR values may be computed with different measures of the same (intrapersonal) travel time distributions of the subjects for comparison purposes. Furthermore, confidence intervals (discussed subsequently) are computed for the mean estimates (ignoring the population density) of the VOR, VOT, and RR of the models.

In this study, a parametric bootstrap approach is adopted to estimate the confidence intervals of the mean estimates (population densities of VOR, VOT, and RR are ignored) of the value of travel time (VOT), of the value of reliability (VOR), and the reliability ratio (RR) for the econometric models. Generally, bootstrapping consists of resampling the data to obtain several samples of a specific size, and the statistics of interest are estimated for each sample. This process is repeated a particular number of times (i.e. bootstrap replication). In this case, the estimates and standard errors of interest are stored for each of the bootstrap replications, and the counterpart bootstrap estimates may be computed. Furthermore, an underlying assumption of the distribution of the parameters statistics means that the bootstrap is parametric. See Cameron and Trivedi (2005) Chapter 11 for details about bootstrap methods.

The Krinsky-Robb (parametric) bootstrap (Krinsky and Robb, 1986; Krinsky and Robb, 1990) is a method to estimate the confidence intervals that consists of taking a large number of draws from a multivariate distribution formed by the estimated coefficients and covariance from the proposed econometric model. Simulated values of VOR, VOT, and RR are calculated for each of the draws taken from the joint distribution of the estimated coefficients of the econometric model. This approach can be computationally intensive but much less than the nonparametric bootstrap (which makes no assumption on the underlying distribution of the statistics). In this study, 1000 replications were employed. The number of replication was chosen until no significant difference was found across confidence interval estimates due to the number of replications. Furthermore, the authors initially considered a nonparametric bootstrap approach because it is likely to be more robust (as it does not make any assumption about the distribution of the coefficients). However, the high computational costs of estimating mixed logit models with 250 Halton draws, and also using a significant number of bootstrap replications (at least 400 replications are required according to Cameron and Trivedi (2005)). The number of bootstrap replication should be adjusted in 
order to reduce the sensitivity of the confidence interval estimates with respect to the number of replications, and thus this requires increased computing time that is impractical. In addition, Hole (2007a) discusses that the nonparametric bootstrap is the most robust (for estimating confidence intervals of willingness-to-pay measures), but his findings note that none of the other methods (including Krinsky-Robb) produce wildly inaccurate estimates.

\section{Results}

A first step in this study was to identify the characteristics affecting the route choice process of the subjects after allowing them to acquire new information about the alternatives. This information refers to the 6-weeks route assignment period used to familiarize the subjects with each of the studied alternatives (see Sections 3 and 6.1). Each of the Models (see Table 8) found as statistically significant the following factors: travel time, travel time variability, toll cost, and a dislike of the HOT lanes in comparison to arterials (alternative specific constant for HOT). Both the centrality measure of travel time and travel time variability are directly linked to the travel time distribution experienced by each traveler. Therefore, the fact that both are statistically significant factors in explaining the route choice variation is likely to translate into an added influence to the behavioral decision-making process of the subjects.

In addition, observed (see Table 8) and unobserved heterogeneity of the travelers were found to be statistically significant as well. In the case of observed heterogeneity, males were found to be more risk-prone than females in most of the models. This is illustrated by the fact that they have a smaller disutility for choosing routes with higher variability, in contrast to the females which have higher disutility. This result corroborates Abdel-Aty et al. (1997). The authors searched the collected survey data in order to identify a culprit for such a discrepancy, and the plausible reason is linked to the non-work activities (e.g. childcare, personal business) of the subjects. However, further research is required with the data to quantify the non-work trips, and study the travel patterns of such trips. In the case of unobserved heterogeneity, additional sources (e.g. individual idiosyncrasies) unknown to the researcher were found to influence the route choices of the travelers. This result agrees with Small et al. (2005) and Small et al. (2006), because of presence of the effect.

Table 8

Econometric models.

\begin{tabular}{|c|c|c|c|c|c|c|}
\hline $\begin{array}{l}\text { Subjects: 18/observations: } 219 \\
\text { Arterial vs. GPL vs. HOTL }\end{array}$ & $\begin{array}{l}\text { Mean } / S^{a b} \\
\text { Estimate }\end{array}$ & $\begin{array}{l}\text { Mean/RR }{ }^{\mathrm{ab}} \\
\text { Estimate }\end{array}$ & $\begin{array}{l}\text { Mean/IQR }{ }^{\mathrm{ab}} \\
\text { Estimate }\end{array}$ & $\begin{array}{l}\text { Median } / S^{\mathrm{ab}} \\
\text { Estimate }\end{array}$ & $\begin{array}{l}\text { Median/RR }{ }^{\mathrm{ab}} \\
\text { Estimate }\end{array}$ & $\begin{array}{l}\text { Median/IQR } \\
\text { Estimate }\end{array}$ \\
\hline \multicolumn{7}{|l|}{ Travel time $e^{a}$} \\
\hline Mean & $-0.514^{* * *}$ & $-0.468^{* * *}$ & $-0.485^{* * *}$ & $-0.316^{* * *}$ & $-0.475^{* * *}$ & $-0.313^{* * *}$ \\
\hline Std. dev. & $0.320^{* *}$ & $0.333^{* *}$ & $0.283^{* *}$ & $0.200^{* *}$ & $0.270^{* *}$ & 0.137 \\
\hline$\%$ Positive & 5.41 & 8.00 & 4.33 & 5.71 & 3.93 & 1.12 \\
\hline \multicolumn{7}{|l|}{ Travel time variability $^{b}$} \\
\hline Mean & $-0.483^{* * *}$ & $-0.290^{* * *}$ & $-0.521^{* * *}$ & $-0.504^{* * *}$ & $-0.540^{* * *}$ & $-0.330^{* * *}$ \\
\hline Std. dev. & 0.00110 & 0.00112 & $0.152^{*}$ & $0.195^{* *}$ & $0.189^{* *}$ & $0.240^{* *}$ \\
\hline \% Positive & 0.00 & 0.00 & 0.03 & 0.49 & 0.21 & 8.46 \\
\hline Male-travel time variability ${ }^{\mathrm{d}}$ & $0.373^{* *}$ & $0.247^{* *}$ & $0.500^{* *}$ & 0.181 & $0.313^{* *}$ & \\
\hline Toll cost $\mathrm{t}^{\mathrm{c}}$ & $-3.371^{* *}$ & $-3.55^{* *}$ & $-3.98^{* *}$ & $-2.44^{*}$ & $-3.91^{* *}$ & $-2.58^{*}$ \\
\hline $\mathrm{PM}^{g}-\mathrm{GPL}$ & -0.662 & -0.571 & -0.607 & -0.599 & 0.184 & 0.130 \\
\hline $\mathrm{PM}^{g}-\mathrm{HOT}$ & -0.215 & 0.379 & 0.0659 & 0.199 & -1.04 & -0.614 \\
\hline \multicolumn{7}{|l|}{ Previous choice - GPL $L^{\mathrm{e}}$} \\
\hline Mean & 0.154 & 0.379 & 0.167 & 0.287 & 0.370 & 0.339 \\
\hline Std. dev. & 0.00374 & 0.0316 & 0.754 & 0.069 & 0.0985 & 0.311 \\
\hline \multicolumn{7}{|l|}{ Previous choices - HOT } \\
\hline Mean & 0.292 & 0.205 & 0.707 & 0.786 & 0.329 & 1.36 \\
\hline Std. dev. & 0.0699 & 0.115 & 0.0259 & 0.0244 & 0.104 & 0.0263 \\
\hline ASC - GPL & -0.218 & -0.230 & -0.313 & -0.278 & -0.229 & -0.567 \\
\hline ASC - HOT & $-2.22^{* *}$ & $-1.93^{* *}$ & $-2.156^{* *}$ & $-2.10^{* *}$ & $-1.86^{*}$ & $-2.62^{* *}$ \\
\hline Intercept Log-likelihood $^{\mathrm{f}}\left(L L_{A \hat{S} C}\right)$ & -182.21 & -182.21 & -182.21 & -182.21 & -182.21 & -182.21 \\
\hline Convergence log-likelihood $\left(L L_{\hat{\beta}}\right)$ & -102.807 & -113.213 & -108.287 & -113.540 & -110.360 & -121.161 \\
\hline Likelihood ratio index $\left(\rho^{2}\right)$ & 0.436 & 0.379 & 0.406 & 0.377 & 0.394 & 0.335 \\
\hline
\end{tabular}

${ }^{a b c d e}$ Readers should refer to Section 6.1 for more information.

ab Centrality/Dispersion. It represents the centrality measure for travel time variable, and dispersion measure for travel time variability variable in the models.

c It is the toll paid by each subject for a choice situation (or occasion).

d It is an interaction variable between gender and the respective travel time variability measure.

e It is a one period lagged variable included in the alternative.

${ }^{f}$ It is the value of the loglikelihood function for a model with only alternative specific constants.

* Significance at $10 \%$ level.

** Significance at $5 \%$ level.

*** Significance at $1 \%$ level. 
A second step was examining the performance, and likely meaning of the travel time variability measures. In Table 8, the Mean/SD, Mean/IQR, and Median/RR models fit the data better, and statistically significant at 5\% according to likelihood ratio tests. However, the Mean/SD model has the best fit for this data, and the Median/IQR has the lowest goodness of fit of the models. Furthermore, the Median/RR outperformed its other counterparts among the models with median as the centrality measure.

A third step was to analyze the results of the random coefficients (unobserved heterogeneity) and state dependency in the models. In Table 8, most models (except Median/IQR) exhibit a statistically significant variation across the population for the centrality measure (mean or median of the travel time), and only the Median models (and Mean/IQR) have also a statistically significant variation for the travel time variability. This result is interesting because it indicates that travelers differ on the disutility they gain for similar centrality measures of travel times, and also for travel time variability at least for the median models (and Mean/IQR). Additionally, the normal distribution is a reasonable choice for our random coefficients as the percentage of theoretically unsound values (e.g. positive travel time utility) is small (less than $8 \%$ ). In the case of state dependency, the first lagged variables of the choices were not found statistically significant. This result is plausible as none of the subjects had any previous experience with the HOT lanes (and in some cases the arterials), and thus the subjects were likely to be exploring for new alternatives after learning about their possible choices during the 6 -weeks route assignment period.

In addition, the time of day variables were not found statistically significant, and thus indicating not significant variations among trips in the morning vs. trips in the afternoon. Other specifications were considered including weather related variables, and income level dummy variables but were dropped because they were not statistically significant. In the case of the income-level variables, it was found that including them along with gender variables allowed for the coefficients of the model to be jointly statistically not significant (i.e. different) from zero according to likelihood ratio tests. In addition, the incomelevel variables included without gender variables did not statistically made the model fit the data better vs a model without the income-level variables and without the gender variables. Another model also was specified with a travel time variability measure of a shortened left range (50th-10th), but it was not statistically significant as well.

Finally, the last step was the estimation of the value of reliability (VOR), value of time (VOT), and the reliability ratio (RR) for the models specified according to Section 6.1, and results presented in Tables 9, and 10.

In Table 9, it is found that the value of travel time (VOT) estimates are not different across models (i.e. centrality measures), except for the Mean/SD model (it is higher than others by 1 to 2 US dollars). The confidence intervals estimated indicate (besides the imprecision of the estimates largely due to the presence of heterogeneity) that the VOT estimates across models are contained in the estimated confidence intervals across models. It should be noted that the confidence intervals for Median/SD, and Median/IQR do contain USD\$0.00 as a possible value, and thus their VOT estimates should be discarded in comparison to other models, which do not contain USD $\$ 0.00$ within their confidence intervals. Moreover, it is found that the value of travel time reliability (VOR) estimates are quite different by gender; VOR for women in the sample are significantly higher in comparison to VOR estimates for men. The authors searched the collected survey data, and believe a plausible

Table 9

Comparison of VOT and VOR estimates.

\begin{tabular}{|c|c|c|c|c|}
\hline \multirow[b]{2}{*}{ Arterial vs. GPL vs. HOTL } & \multirow{2}{*}{$\begin{array}{l}\text { VOT (US\$/Hr) } \\
\text { Mean }{ }^{\mathrm{a}} / \text { confidence interval 95\% }\end{array}$} & \multicolumn{3}{|c|}{ VOR (US\$/Hr) } \\
\hline & & Men $^{\mathrm{b}}$ & Women $^{\mathrm{b}}$ & Mean $^{\mathrm{a}} /$ confidence interval 95\% \\
\hline Mean/SD & $9.15(2.46,29.71)$ & 1.96 & 8.60 & $5.99(2.37,30.42)$ \\
\hline Mean/RR & $7.92(2.67,31.45)$ & 0.73 & 4.90 & $4.25(1.19,21.74)$ \\
\hline Mean/IQR & $7.31(2.86,25.51)$ & 0.32 & 7.85 & $4.40(1.68,18.91)$ \\
\hline Median/SD & $7.77(-11.16,49.79)$ & & & $11.31(-19.74,61.43)$ \\
\hline Median/RR & $7.30(2.72,25.47)$ & 3.48 & 8.29 & $5.98(2.55,22.94)$ \\
\hline Median/IQR & $7.31(-4.67,42.34)$ & & & $7.68(-5.62,39.12)$ \\
\hline
\end{tabular}

a VOT and VOR estimates and confidence intervals are calculated using the Krisnky-Robb parametric bootstrap with 1000 replications. Only the mean estimates of the mixed logit models are bootstrapped.

b Only mean estimates of VOR are obtained for men and women.

Table 10

Comparison of reliability ratio estimates.

\begin{tabular}{|c|c|c|c|}
\hline Arterial vs. GPL vs. HOTL ${ }^{\mathrm{a}}$ & Men $^{b}$ & Women $^{\mathrm{b}}$ & Mean ${ }^{\mathrm{a}} /$ confidence interval 95\% \\
\hline Mean/SD & 0.21 & 0.94 & $0.82(0.46,1.58)$ \\
\hline Mean/RR & 0.092 & 0.62 & $0.58(0.23,1.10)$ \\
\hline Mean/IQR & 0.043 & 1.07 & $0.65(0.35,1.07)$ \\
\hline Median/SD & & & $1.50(0.83,3.03)$ \\
\hline Median/RR & 0.48 & 1.14 & $0.86(0.47,1.45)$ \\
\hline Median/IQR & & & $1.05(0.49,2.13)$ \\
\hline
\end{tabular}

${ }^{a}$ Reliability Ratios estimates and Confidence Intervals are calculated using the Krisnky-Robb parametric bootstrap with 1000 replications. Only the mean estimates of the mixed logit models are bootstrapped.

b Only mean estimates of reliability ratio are obtained for men and women. 
reason is linked to the non-work activities (e.g. childcare) of the subjects. However, it is necessary to further explorer the travel patterns for the subjects in order to identify whether women in the sample had more activities within a day in comparison to men in the sample. In addition, the confidence intervals for the VOR estimates (without considering gender differences) indicate that all the estimates are within the intervals across models. The variation of size of the estimates is more prevalent in VOR estimates in comparison to VOT estimates. However, the VOR estimates from the Median/SD, and Median/ IQR model also contain USD\$0.00 as a possible value. Thus, the VOR estimates from these models should be discarded in favor of the VOR estimates of the other models; these estimates are also the highest. It should also be noted that in terms of precision the estimated confidence intervals of Mean/IQR and Median/RR are the least imprecise. The results in Table 9 indicate that care must be taken by researchers when choosing a centrality and dispersion measure, and that confidence intervals should be estimated in order to guarantee that the measure is reasonable (e.g. USD $\$ 0.00$ is not a possible candidate). It is also found that the confidence intervals overlap for the VOT estimates is high, but for the VOR estimates it is much less so, and thus the question becomes whether an estimate contained in all models confidence intervals should be preferred. It should also be noted that only the mean estimates of population densities for VOT and VOT were bootstrapped.

In Table 10, the variation of reliability ratios across models is significant. However, it is clear that the mean values of the RR estimates are contained within the confidence intervals across models, except for the RR of the Median/SD model. Also, the confidence intervals are quite large due to the presence of heterogeneity as previously noted. Lastly, it is found that the reliability ratio (RR) estimates are quite different by gender; RR for women in the sample are significantly higher in comparison to RR estimates for men. It is believed that a plausible reason is linked to the non-work activities (e.g. childcare) of the subjects as previously noted. Also, only the mean estimates of population densities for RR were bootstrapped.

\section{Conclusions}

The prominent features of this study are: the experimental design (ACERP) employed for the GPS/Transponder data collected; and the use of mixed logit models to estimate the VOT, VOR and RR for this RP data. The first component allowed the generation of plausible scenarios (assigned routes with actual OD pairs) for the subjects to experience in real life conditions. This provided several benefits already mentioned despite its main difficulty being the high attrition rate. This experimental design serves as a basis for researchers to further develop it. A future improvement is to study whether the costs of acquiring a MnPass transponder are non-negligible, and may have biased the estimates of the toll cost variable. Moreover, the study found to be beneficial the experience with GPS devices for travel behavior research. These were found to be quite useful for obtaining detailed commute level data. It permitted direct measurement of travel time and variability values for each of the subject's trips and specific routes. The wealth of information obtained has yet to be fully exploited. The second component allowed for the investigation of the effects of travel time reliability in the route choice behavior of travelers. These effects were evaluated in two parts. First, the attributes (including unobserved heterogeneity) of the subjects that were significant for route choices were recognized. Readers should refer to Table 8. Second, values of reliability were estimated according to distinct proposed travel time variability measures. A summary of VOT, VOR and RR can be found in Tables 9 and 10 . Furthermore, the results are reasonable despite the low VOT/VOR estimates obtained from the data. The results are highly statistically significant (at least 5\%) despite the small sample of subjects, and thus this is likely an indication of effects of large size (this is very common in the medical research literature, and Lieber (1990) provides an excellent discussion of it). Moreover, the confidence intervals of the estimates contain the mean estimates of other studies, and are similar to the range of confidence intervals of other studies (e.g. Small et al., 2005; Small et al., 2006).

Future research includes the development of models using this RP and SP data to develop VOR as function of time similar to Liu et al. (2007), in order to asses the different time periods for which users will be willing to pay higher tolls. This leads to the possible interpretation that VOR as a function of time could possibly help set toll prices more effectively than traffic flow measures by itself. However, this hypothesis needs to be tested.

\section{Acknowledgments}

This study is supported by the Oregon Transportation Research and Education Consortium (2008-130 Value of Reliability and 2009-248 Value of Reliability Phase II). We would also like to thank Kathleen Harder, John Bloomfield, Shanjiang Zhu for collaborating in survey design and data collection. In addition, the collaboration of Brian Corcoran (at MnPass.net) in providing the authors with a I-394's toll database is highly appreciated.

\section{References}

2006-2008 American Community Survey 3-Year Estimates. Minneapolis-St. Paul-Bloomington. MN-WI Metropolitan Statistical Area, Retrieved November 25, 2009. (n.d.). <http://factfinder.census.gov/>.

Abdel-Aty, M., Kitamura, R., Jovanis, P., 1997. Using stated preference data for studying the effect of advanced traffic information on drivers' route choice. Transportation Research Part C 5, 39-50.

Bartram, D.J., 1980. Comprehending spatial information: the relative efficiency of different methods of presenting information about bus routes. Journal of Applied Psychology 65, 103-110.

Bates, J., Polak, J., Jones, P., Cook, A., 2001. The valuation of reliability for personal travel. Transportation Research Part E 37, $191-229$.

Ben-Akiva, M., Lerman, S., 1985. Discrete Choice Analysis: Theory and Application to Travel Demand. MIT Press.

Blaauw, G.J., 1982. Driving experience and tasks demands in simulator and instrumented car: a validation study. Human Factors $24,473-486$. 
Bovy, P., Stern, E., 1990. Route Choice: Wayfinding in Transport Networks. Kluwer Academic Publishers, Netherlands.

Cameron, A.C., Trivedi, P.K., 2005. Microeconometrics: Methods and Applications. Cambridge Univ. Press.

Carrion, C., Levinson, D., 2012. Value of reliability: a review of the current evidence. Transportation Research Part A 46, 720-741.

Chang, M.F., Herman, R., 1978. An attempt to characterize traffic in metropolitan areas. Transportation Science 12, 59-79.

Chang, X., Stopher, P., 1981. Defining the perceived attributes of travel modes for urban work trips. Transportation Planning and Technology 7, 55-65.

D'Este, G., 1986. Route preference surveys and possible network flows. In: 8th Conference of Australian Institute of Transportation Research, Australia.

Duffell, J.R., Kalombaris, A., 1988. Empirical studies of car driver route choice in hertfordshire. Traffic Engineering and Control, 398-408.

Gaver, D., 1968. Headstart strategies for combating congestion. Transportation Science 2, 172-181.

Godley, S.T., Triggs, T., Fildes, B., 2002. Driving simulator validation for speed research. Accident Analysis and Prevention 34, 589-600.

Goldin, S.E., Thorndyke, P.W., 1982. Simulating navigation for spatial knowledge acquisition. Human Factors 24, 457-471.

Hensher, D., 1994. Stated preference analysis of travel choices: the state of practice. Transportation 21, 107-133.

Hess, S., 2005. Advanced Discrete Choice Models with Applications to Transport Demand. Ph.D thesis. Imperial College London, UK.

Hess, S., Bierlaire, M., Polak, J.W., 2005. Estimation of value of travel-time savings using mixed logit models. Transportation Research Part A 39, 221-236.

Hole, A., 2007a. A comparison of approaches to estimating confidence intervals for willingness to pay measures. Health Economics 16, 827-840.

Hole, A., 2007b. Fitting mixed logit models using maximum simulated likelihood. Stata Journal 7, 388-401.

Hsiao, C., 2003. Analysis of Panel Data, second ed. Cambridge Univ. Press.

Jackson, W., Jucker, J., 1982. An empirical study of travel time variability and travel choice behavior. Transportation Science 16, 460-475.

Johannesson, M., Lundin, D., 2002. The impact of physician preferences on the prescription of new drugs. In: SE/EFI Working Paper Series in Economics and Finance No. 460.

Khattak, A., Koppelman, F., Schofer, J., 1993. Stated preference for investigating commuters' diversion propensity. Transportation 20, $107-127$.

Krinsky, I., Robb, A., 1986. On approximating the statistical properties of elasticities. Review of Economics and Statistics 68, 715-719.

Krinsky, I., Robb, A., 1990. On approximating the statistical properties of elasticities: a correction. Review of Economics and Statistics 72, 189-190.

Leiser, D., Stern, E., 1988. Determinants of subjective time estimates in simulated urban driving. Transportation Research Part A 22, 175-182.

Levinson, D., Harder, K., Bloomfield, J., Carlson, K., 2006. Waiting tolerance: ramp delay vs. freeway congestion. Transportation Research Part F: Traffic Psychology and Behaviour 9, 1-13.

Levinson, D., Harder, K., Bloomfield, J., Winiarczyk, K., 2004. Weighting waiting: evaluating the perception of in-vehicle travel time under moving and stopped conditions. Transportation Research Record: Journal of the Transportation Research Board 1898, 61-68.

Li, H., 2004. Investigating Morning Commute Route Choice Behavior Using Global Positioning Systems and Multi-day Travel Data. Ph.D thesis. Georgia Institute of Technology, USA.

Li, H., Guensler, R., Ogle, J., 2005. Analysis of morning commute route choice patterns using global positioning system-based vehicle activity data. Transportation Research Record: Journal of the Transportation Research Board 1926, 162-170.

Li, H., Guensler, R., Ogle, J., Wang, J., 2004. Using global positioning system data to understand day-to-day dynamics of morning commute behavior. Transportation Research Record: Journal of the Transportation Research Board 1895, 78-84.

Li, Z., Hensher, D., Rose, J., 2010. Willingness to pay for travel time reliability in passenger transport: a review and some new empirical evidence. Transportation Research Part E 46, 384-403.

Lieber, R., 1990. Statistical significance and statistical power in hypothesis testing. Journal of Orthopaedic Research 8, 304-309.

Liu, H., He, X., Recker, W., 2007. Estimation of the time-dependency of values of travel time and its reliability from loop detector data. Transportation Research Part B: Methodological 41, 448-461.

Louviere, J., Hensher, D., Swait, J., 2000. Stated Choice Methods: Analysis and Applications. Cambridge University Press.

Mahmassani, H.S., Herman, R., 1989. Interactive experiments for the study of tripmaker behaviour dynamics un congested commuting systems. In: Oxford Conference on Travel Behaviour.

Nakayama, S., 2010. A review of value of reliability of road transportation. In: Presented at the 4th International Symposium on Transportation Network Reliability in Minneapolis, MN, USA.

Nicholson, A., Du, Z., 1997. Degradable transportation systems: an integrated equilibrium model. Transportation Research Part B 31, $209-223$.

Nicholson, A., Schmocker, J., Bell, M., Iida, Y., 2003. Assessing transport reliability: Malevolence and user knowledge. In: The Network Reliability of Transport, Proceedings of the 1st International Symposium on Transportation Network Reliability, pp. 1-22.

Noland, R., Polak, J., 2002. Travel time variability: a review of theoretical and empirical issues. Transport Reviews, vol. 22, Routledge, Part of the Taylor \& Francis Group, pp. 39-54.

Noland, R., Small, K., 1995. Travel-time uncertainty, departure time choice, and the cost of morning commutes. Transportation Research Record 1493, 150158.

Orro-Arcay, A., 2005. Modelos de eleccion discreta en transportes con coeficientes aleatorios [Discrete Choice Models in transportation with random coefficients], Ph.D thesis. Universidad de A Coruna, Spain.

Ortuzar, J., Willumsen, L., 2011. Modelling Transport, fourth ed. Wiley.

Pal, A., 2004. Modeling of Commuter's Route Choice Behavior. Master's thesis. The University of Toledo, USA.

Prashker, J., 1979. Direct analysis of the perceived importance of attributes of reliability of travel modes in urban travel. Transportation 8, 329-346.

Scott, D., 1985. Driving simulator to aid road safety. Automotive Engineering 93, 79-82.

Sillano, M., Ortuzar, J.D., 2005. Willingness-to-pay estimation with mixed logit models: some new evidence. Environment and Planning A 37, 525-550.

Small, K., 1982. The scheduling of consumer activities: work trips. American Economic Review, vol. 72. The American Economic Association, pp. 467-479.

Small, K., Verhoef, E., 2007. The Economics of Urban Transportation. Routledge, Part of the Taylor \& Francis Group.

Small, K., Winston, C., Yan, J., 2005. Uncovering the distribution of motorists' preferences for travel time and reliability. Econometrica 73, 1367-1382.

Small, K., Winston, C., Yan, J., 2006. Differentiated road pricing, express lanes, and carpools: exploiting heterogeneous preferences in policy design. Brookings-Wharton Papers on Urban Affairs 7, 53-96.

Tilahun, N., Levinson, D., 2009. Travel Demand Management and Road User Pricing: Success, Failure and Feasibility. Ashgate Publishers, Chapter Unexpected Delay and the Cost of Lateness on I-394 High Occupancy/Toll Lanes. pp. 173-184.

Tilahun, N., Levinson, D., 2010. A moment of time: reliability in route choice using stated preference. Journal of Intelligent Transportation Systems 14, 179187.

Train, K., 2009. Discrete Choice Methods with Simulation, second ed. Cambridge University Press.

Vaziri, M., Lam, T.N., 1983. Perceived factors affecting driver route decisions. Journal of Transportation Engineering 109, $297-311$.

Wong, H., Sussman, J., 1973. Dynamic travel time estimation on highway networks. Transportation Research 7, 355-370.

Zhang, L., Levinson, D., 2008. Determinants of route choice and the value of traveler information: a field experiment. Transportation Research Record: Journal of the Transportation Research Board 2086, 81-92. 